\title{
A dimensão internacional da obra de Celso Furtado
}

\author{
Marcos Costa Lima \\ Universidade Federal de Pernambuco, Brasil \\ (iD) https://orcid.org/0000-0002-3831-7631 \\ marcosf costalima@gmail.com
}

Faz uns cinco anos que havia pensado em escrever algo sobre Celso Furtado como um autor das relações Internacionais. De fato, a ideia tomou outra dimensão ao elaborar um projeto, que seria apresentado ao Centro Internacional Celso Furtado de Políticas para o Desenvolvimento, com mais tempo para estabelecer uma análise mais densa e capaz de dar um quadro abrangente do economista brasileiro. Alguns estudos realizados evidenciavam que o campo das relações internacionais na América Latina era órfão em autores reconhecidos internacionalmente, seja por um exacerbado predomínio do pensamento, sobretudo, estadunidense e anglo-saxão; seja por estar fortemente orientado por pensadores direta ou indiretamente vinculados ao governo ou think-tanks próximos ao Departamento de Defesa dos EUA, seja por uma aceitação acrítica ou mimética dos que fazem o campo na região. ${ }^{1}$ Em um dos livros clássicos das Relações Interna-

1. Ver Robert Gilpin; George F. Kennan; Henry Kissinger; Zbigniew Brzezinski 
cionais (RI), Robert Gilpin (2002, p. 19-20) afirma que “uma compreensão do comércio, das relações monetárias e do desenvolvimento econômico exige a integração da perspectiva teórica das disciplinas da economia e da ciência política (...)”. E mais adiante diz que “(...) Nos últimos séculos cresceu a interdependência das economias nacionais, em virtude do aumento dos fluxos de comércio, do intercambio financeiro e tecnológico (...)” explicitando que a expansão da consciência econômica, bem como da democracia política “(...) levou a uma percepção quase universal de que o Estado pode ser usado para produzir resultados econômicos, e, em particular, para redistribuir a riqueza em favor de determinadas pessoas ou grupos”.

Poderíamos dar continuidade à leitura desse importante livro que é A Economia Política das Relações Internacionais, mas julgo suficiente para meus propósitos esta breve alusão ao clássico de Gilpin. O que me interessa aqui é dizer de forma clara, que Celso Furtado, ao longo de sua vasta obra, tratou dos mesmos temas e especialidades tratadas por Gilpin. A questão que fica, portanto é a seguinte: Por que uma obra, ou o conjunto da obra de Furtado não é considerado como uma produção acadêmica no campo das Relações Internacionais? Nem no Brasil, nem na América Latina ou ainda menos em termos internacionais. Não vá se argumentar que escrevia em português, pois seus livros foram traduzidos para o inglês, francês, espanhol, italiano, mandarim, japonês, persa, sueco, polonês. Essa é a questão que move esse artigo, contribuir para que o pensamento de Celso Furtado seja considerado como uma formulação também do campo das Relações Internacionais.

Leitor a longo tempo da obra de Celso Furtado sempre o consi-

Stephen David Krasner; Charles P. Kindleberger; Hans Morgenthau; Joseph Samuel Nye Jr. entre muitos outros. 
derei um autor maior, principalmente no subcampo disciplinar que é a Economia Política Internacional (EPI) e não aceitava este tipo de discriminação colonial ou pós-colonial.

Na trajetória de Furtado, acompanhando a Apresentação feita por Rosa Freire d’Aguiar Furtado (2009), que nos fala do relatório final de Celso apresentado à Fundação Rockfeller, ao término de sua bolsa, fica-nos a reflexão abrangente de Celso, antes mesmo de iniciar a escrita de Formação Econômica do Brasil, a sua extrema atenção em entender o processo brasileiro enquanto "um episódio da expansão comercial da Europa” (FURTADO, 2009, p. 49). Ele nos diria então:

Interessei-me por algum tempo pelo estudo dos fatores internacionais que, durante o século XIX travaram o desenvolvimento das economias latino-americanas e promoveram a expansão dos Estados Unidos. Penso que minhas ideias sobre esse ponto estão muito mais claras agora e espero ser capaz de preparar e publicar mais adiante uma análise comparativa do papel do comércio internacional nos primeiros estágios do desenvolvimento econômico dos Estados Unidos e da América Latina.

Ao retomarmos a Parte Um e seus sete capítulos, de Formação Econômica do Brasil, tratam em boa medida da história e da expansão economia europeia e chega a dizer que “o início da ocupação econômica do território brasileiro é em boa medida uma consequência da pressão política exercida sobre Portugal e Espanha pelas demais nações europeias” (FURTADO, 2009, p. 51).

Para a consecução deste artigo, selecionei um conjunto de livros de Celso Furtado, que a meu juízo deixam explícito a sua visão de internacionalista e chega a ser esdrúxulo e fora do lugar que muito raramente se menciona o autor como um pensador do campo.

No prefácio de sua Formação Econômica da América Latina, que dedica a seus alunos da Universidade de Paris, Furtado é taxativo ao 
discutir os temas do subdesenvolvimento/desenvolvimento, seu duplo propósito para escrever este livro, a saber, de ajudar o estudioso a formar uma ideia do perfil econômico da região latino-americana e de contribuir para ampliar a perspectiva dos estudos de desenvolvimento dentro de cada país latino-americano. Desta forma entende que a compreensão do Brasil a partir de meados do século XIX "requer a sua inserção no quadro regional, da mesma forma que exige uma nítida percepção do comportamento dos polos dinâmicos da economia mundial” (FURTADO, 1969, p. 10). Mais à frente, no Capítulo $I V$, dedicado a transformação do comércio internacional, na segunda metade do século XIX, trata da divisão internacional do trabalho e o lugar da América Latina neste processo e novamente reitera o que disse no prefácio: "No correr do século compreendido entre os anos de 1800 e o primeiro conflito mundial, implantou-se um esquema de divisão internacional do trabalho e tomou forma um sistema de economia mundial" (FURTADO, 1969, p. 57).

Mas o autor não apenas reitera e explicita a formação de um sistema mundial, mas o qualifica em três pontos: 1 . A existência de um núcleo avançado de capitalização, que concentra a atividade industrial, seus equipamentos e inovação, e também um núcleo financiador das exportações mundiais de bens de capital, que controla a infraestrutura dos transportes do comércio internacional, e centro das importações de bens primários; 2. A formação de um sistema de divisão internacional do trabalho sobre hegemonia basicamente da Inglaterra e um estimulo à especialização que favorece o rápido povoamento dos grandes espaços vazios das regiões de clima temperado e a articulação de outras áreas ao mercado mundial mediante a exportação de matérias primas; e, 3. O estabelecimento de uma rede de transmissão do progresso tecnológico que se mantém concentrada geograficamente 
(FURTADO, 1969. p. 60-61).

Há um livro em especial, que corrobora para a hipótese que eu tento desenvolver aqui, a saber, que Celso Furtado para além de um economista, é um internacionalista, é um autor do campo das Relações Internacionais; trata-se de Subdesenvolvimento e Estagnação na América latina, publicado em 1968, e em cujo Capítulo 1 assim considera: "Na análise que se segue, trataremos de captar o problema do subdesenvolvimento como uma realidade histórica, decorrente da propagação da técnica moderna no processo de constituição de uma economia em escala mundial” (FURTADO, 1968, p. 3). Ou seja, os fenômenos do subdesenvolvimento e estagnação de uma região, a América Latina, são vistos como elementos do capitalismo que se configuram em escala mundial. Ou seja, o subdesenvolvimento não pode ser analisado como uma fase do processo, nem pode reproduzir a experiência das economias que lideram um sistema econômico de base mundial, que incorporaram progresso tecnológico, que por sua vez lhes permitiu crescimento, melhores salários e também relativa estabilidade social, conseguida via pressão social dos trabalhadores.

No caso da América Latina o caminho foi diverso, fomos integrados progressivamente ao sistema capitalista, aos mercados mundiais, através de exportação de produtos primários, utilizando muita mãode-obra, no início mão-de obra escrava e recursos naturais. Como afirma:

A industrialização latino-americana não é o resultado da intenção consciente de romper com esquemas tradicionais da divisão do trabalho. Ela tomou impulso durante o longo período de depressão nos mercados internacionais de produtos primários, iniciado com a crise de 1929 (FURTADO, 1968, p. 7).

Esta industrialização se constitui como um caso típico, realizado 
através da substituição de importações (ISI). E aí já levamos desvantagem, pois, diferentemente dos países centrais, a ISI ocorreu quando a tecnologia disponível trabalhava na direção de poupar mão-de-obra, quando tínhamos grande excedente de trabalhadores. Disso derivam os baixos salários, que penalizavam a geração de poupança e de investimentos. Furtado apresenta dados evidenciando que durante os anos 1950 ocorreu um aumento da produção industrial para 6,2\%, quando diminuía a taxa de ocupação nas indústrias para 1,6\%. Portanto, a industrialização "substitutiva” constitui processo qualitativamente diferente do que ocorria nos países desenvolvidos (FURTADO, 1968, p. 109). Aqui, a tecnologia na forma que se introduzia, criava problemas sociais. Não era fácil, à época, nem o é hoje, dizer que dada certas condições históricas de um país, ou uma região, a tecnologia pode ter efeito deletério. Um exemplo marcante é o atraso de nossa agricultura pela persistência de formas de organização semifeudal no campo, no Nordeste, sobretudo. Diz Furtado nesse livro que a nossa agricultura era baseada em técnicas rudimentares e mais, que exauriam a fertilidade do solo. Analisa ainda, com dados censitários de 1960, que mais de 90\% das terras agricultáveis no Brasil, estavam em mãos de médias e grandes propriedades, com um agravante: elas não utilizavam mais de 8\% dessas terras em cultivos. Diz Furtado (1968, p. 103) com descortino: "não é de surpreender que nos países latinoamericanos o processo político gere fortes tensões que comprometem, permanentemente a estabilidade das estruturas de poder”. Esta frase, escrita há 68 anos, ainda é justa, a julgar pelos acontecimentos recentes em toda a região.

Mas é no Capítulo 2, do livro que ora discutimos, onde Celso Furtado, de forma magistral, estabelece uma rica análise geopolítica da região. Para tanto, vai acionar autores de referência das relações In- 
ternacionais, como George F. Kenan, que foi assessor diplomático do presidente Truman, bem como Hans Morgenthau², um dos autores clássicos da "Escola realista”. A peça central do artigo são os Estados Unidos da América e a particularidade de suas relações com a América latina:

[...] a margem de autodeterminação, na busca de meios para enfrentar a tendência à estagnação econômica, reduz-se dia a dia, na medida em que imperativos da "segurança" dos Estados Unidos exigem crescente alienação de soberania por parte dos governos nacionais. Essa diferença de situação histórica explica, em certa medida, a disparidade das atitudes psicológicas que se observa correntemente entre os povos latino-americanos e a maioria dos países do terceiro Mundo (FURTADO, 1968).

No capítulo deste livro dedicado aos Obstáculos Externos ao Desenvolvimento (FURTADO, 1968), há uma excelente análise que desvela as relações da América Latina e Estados Unidos: o resultado da vitória dos EUA na Segunda Guerra e o estabelecimento de sua hegemonia, daí a Guerra Fria; as exigências de subserviência dos países periféricos - alienação de soberania e as interferências sistemáticas (Doutrina Monroe), como parte de uma área de segurança estabelecida pelos Estados Unidos. A América Central e o Caribe a princípio

2. Morgenthau foi um dos maiores nomes do século XX no estudo da política internacional. Ele foi considerado, junto com Kennan e Reinhold Niebuhr, um dos três grandes autores realistas nos Estados Unidos. Sua obra mais conhecida, Polítics Among Nations, publicada em 1948 foi editada 5 vezes durante sua vida (faleceu em 1980). Há uma tradução excelente e disponível no site da FUNAG. Dizia ele sobre o "realismo": "tendo em vista que vivemos em um universo formado por interesses contrários, em conflito contínuo, não há possibilidade de que os princípios morais sejam algum dia realizados plenamente, razão por que, na melhor das hipóteses, devem ser buscados mediante o recurso, sempre temporário, ao equilíbrio dos interesses e à inevitavelmente precária solução dos conflitos. Assim sendo, essa escola vê em um sistema de controle recíprocos um princípio universal válido para todas as sociedades pluralistas” (2003, p. 4). 
foram os alvos e, depois de Cuba em 1959, deu-se o acirramento. Diz o autor:

O esquema americano de organização de uma sociedade de nações exigiria, para ter êxito na implantação de uma disciplina internacional que as grandes potências ao término da guerra, estivessem , ou aceitassem de uma ou de outra forma, a proeminência dos Estados Unidos de acordo com respeito aos problemas fundamentais de sua política exterior (FURTADO, 1968, p. 147).

É bom lembrar que neste período, a região ainda vivia o sonho do desenvolvimento, vide Juscelino Kubitschek no Brasil, os "50 anos em Cinco”, que se desfez a partir de 1964 em toda a região.

Celso trata da doutrina que, elaborada no Departamento de Estado, e de autoria do historiador diplomata George Kennan - influente junto ao Presidente Truman, que a União Soviética poderia ser "contida”, por vários motivos: uma população já esgotada pelo regime, com uma economia vulnerável e sob a qual pairava grandes incertezas. Mas para isto, os EUA deveriam dar demonstração de coesão, de liderança, não apenas no Ocidente, mas em países da Ásia, como a Coréia do Sul, o Japão, Taiwan, Singapura. Mas se essas reflexões nos fazem hoje pensar no novo conflito que se instala, agora entre EUA e China, Furtado (1968, p. 31) trata da emergência da China naqueles momentos:

Reconhecer a China como um centro autônomo de decisões vem a ser o mesmo que reconhecê-la como potência predominante na Ásia. Isso nos lembra mais uma vez George F. Kennan, seria para os americanos o mesmo que "abandonar (aos chineses) os frutos de nossa vitória sobre o Japão e transformar essa vitória em uma coisa sem sentido". Tratando de prevenir a consolidação da China como potência predominante na Ásia, os americanos ocuparam parte de seu território (Formosa) e criaram uma situação de guerra permanente com esse país. Esse conflito assumiu a forma de uma nova vari- 
ante da guerra fria, em razão do impasse criado por dois fatores: a) a enorme superioridade estratégica dos EUA, a qual retira à China qualquer iniciativa militar e b) a incapacidade dos EUA para "conquistar” militarmente a China. Isto é, ocupar de forma permanente o seu território.

A longa citação vale não apenas pela qualidade da análise, mas também por trazer à tona um fenômeno que, atualizado, traz à cena política um embate hoje bem claro, a saber, o confronto entre China e EUA, agora com novos ingredientes: uma aliança China- Rússia e uma ascensão econômica chinesa que está presente no cotidiano das relações internacionais, que ainda por cima vem sinalizada por uma “decadência” da hegemonia dos EUA, considerada inclusive por grandes autores norte-americanos experts de relações internacionais.

Em 1981, Celso Furtado publica um livro O Brasil Pós-Milagre (FURTADO, 1981), onde em sua Segunda Parte, trata do “Quadro Internacional”, e evidencia não apenas o acompanhamento sistemático da realidade internacional, mas a aguda análise que faz desse contexto, ainda sob os impactos da Guerra Fria. Impressiona no texto, não somente a abordagem sistêmica do período, mas os termos ainda muito atuais para os dias em que vivemos.

Gostaria aqui de introduzir algumas reflexões de Celso, no sentido de reforçar o conjunto de temas que discutia para clarear a dimensão internacional. O economista inicia falando da aceleração do tempo histórico ao final do século XX e entende que uma boa parte dos "especialistas” não tem uma visão adequada da realidade mundial. Ele aponta algo de mais e mais atual, a saber: "o impacto de um desmesurado fluxo de informações nos sistemas de decisões” (FURTADO, 1969, p. 95). Seria como que, dado o êxito do espírito analítico com relação às Ciências da Natureza, de extração cartesiana, os homens estivessem condicionados a explicar o mundo em seus detalhes, sem 
poder apreendê-lo globalmente e, menos ainda, compreendê-lo. É a vitória do conhecimento fragmentado, parcial. Este homem histórico perderia a sensibilidade para entender os riscos de sua própria sobrevivência. A episteme de Furtado aponta, por exemplo, o que chama de "alucinante carreira armamentista”, mas também a destruição do desequilíbrio ecológico, isto há quase 40 anos: “a polarização da humanidade entre sociedades que se permitem um desperdício crescente de recursos e outras em que é alarmante a carência do essencial” (FURTADO, 1969, p. 96). Está apontando um problema que só fez crescer desde então e que compromete a própria reprodução da acumulação capitalista (PICKETTY, 2014; STIGLITZ, 2014; CHESNAIS, 2016; NAYYAR, 2013). Portanto, para Furtado é necessário construir uma visão global da complexa realidade histórica contemporânea como condição para as tendências do capitalismo, que segundo ele está orientada por quatro linhas de força. A primeira sendo a crescente integração dos mercados dos países industrializados capitalistas sob a tutela política e militar dos Estados Unidos. O resultado foi uma crescente concentração do poder econômico, com centros de decisão específicos e em estreita articulação com as grandes corporações transnacionais que, sobretudo, após os choques do petróleo, passam a ganhar independência de seus Estados nacionais, via criação dos paraísos fiscais. Na segunda, Celso aponta os países liderados pela então União Soviética. Na terceira, aponta a crescente carreira armamentista, que deu força e capilaridade à consolidação da hegemonia dos EUA, com imensos reflexos sobre a orientação do avanço tecnológico. Celso reforça a combinação de dois fatores, a saber, a autonomia de decisão das empresas multinacionais e o financiamento público em C\&T com objetivos militares. Finalmente, na quarta, indica a emergência na esfera política internacional do chamado Terceiro Mundo. 
Aqui, Celso Furtado entende, otimisticamente, que estes países tão desiguais teriam condições de "unir forças para modificar a estrutura de poder mundial”, sem o que dificilmente poderiam romper as amarras dessa dependência.

Há que entender que, no tempo em que fala, por um lado certas nações da África e da Ásia conseguem estabelecer suas independências, cujas plataformas “Não-Alinhadas” se expressaram em Bandung, em abril de 1955, mas quando pensamos na América Latina, boa parte de seus países já sofre de regimes ditatoriais alinhados com Washington, num processo longo, que chega aos anos 1980 - quando fala Furtado sobre o endividamento externo da região, submetida a políticas duras de ajuste oriundas do FMI e do Banco Mundial. O confronto entre os EUA e a URSS, para Furtado, é quando "a humanidade alcançou a capacidade de autodestruição antes de haver aprendido a governarse” (FURTADO, 1981, p. 99). Esse confronto, ainda não resolvido no momento do livro de Celso, não obstante já lhe permite afirmar que, graças à Guerra Fria os EUA ganharam legitimidade para estabelecer tutela sobre as demais grandes nações industriais capitalistas, o que criou, segundo ele, as condições objetivas para a afirmação do estilo de desenvolvimento com base em economias de escala, "no uso depredatório de recursos não-renováveis e na uniformização dos padrões de consumo” (FURTADO, 1981, p. 101).

Uma outra consequência relevante foi a aceleração tecnológica, que favoreceu a concentração do poder econômico nos grandes centros capitalistas, submetendo os países periféricos a uma concentração de renda direcionadas aos países ricos, e à transferência de corporações transnacionais para Brasil, México, Argentina e para quase a totalidade da periferia, fenômeno hoje conhecido como "offshorização”. Mas mesmo se levarmos em consideração que quando Celso 
falava em plena Guerra-Fria, já anunciava de certa forma "as frustrações das experiências socialistas”, e, ao mesmo tempo, não deixa de anunciar "o impasse em que se encontra atualmente o sistema capitalista" ao qual atribui como dado fundamental "se queremos perscrutar o futuro" (FURTADO, 1981, p. 103).

A justeza e atualidade de Furtado, em uma obra escrita há quase 40 anos demonstra, no mínimo, os acertos e a qualidade de suas reflexões. Ao referir-se ao "impasse” do capitalismo, num momento em que os EUA estão estabelecendo-se como o grande hegemon, acerta, quando define os múltiplos planos em que se manifestam esse impasse: o primeiro, segundo ele, é a "fronteira ecológica", a tecnologia surgida no quadro do capitalismo industrial, particularmente, a versão que se desenvolveu nos EUA e veio a predominar com a integração dos mercados, prende-se a uma curta visão do tempo, o que explica sua voracidade na utilização de recursos não renováveis (JAMESON, 2014, 2017; LATOUR, 2017; STENGERS, 2009; KLEIN, 2015).

Concluiremos a reflexão sobre o fazer teórico de Celso Furtado, entendendo que sua obra é uma densa abordagem analítica sobre a Política Econômica Internacional naquilo que trata das transformações do capitalismo desde suas origens, com um foco nas relações que estruturam o centro sistêmico e com um olhar especial sobre a periferia capitalista, notadamente o Brasil e a América Latina. A sua teoria do Subdesenvolvimento torna indissociável, tanto em termos político quanto econômicos, a relação que se estabelece e se constrói ao longo do tempo, entre os países que saíram na frente do processo industrial e aqueles late-commers, tornando supérflua a assertiva de que os países mais adiantados só fazem mostrar aos mais atrasados, o seu futuro.

Uma questão me parece inaceitável, é que tantos estudiosos e estudantes da periferia do capitalismo, sobretudo aqueles do campo das 
Relações Internacionais, não incorporem Celso Furtado como um autor desse campo. Uma larga maioria prefere reproduzir os autores canônicos da disciplina, mormente dos Estados Unidos da América, que são, no mais das vezes, funcionários do Estado, assessores do Pentágono, do Sistema de Defesa, ou de Think-tanks que lidam com segurança internacional; guerras e conflitos militares; economia; estratégias e tecnologias, entre outras.

Um dos últimos livros de Celso que faço menção aqui, mas há muitos outros não referenciados, trata-se de Transformação $e$ Crise na Economia Mundial (1987), onde se depara com as fortes mudanças introduzidas no capitalismo, em um mundo cada vez mais desregulado. Trata e dá conta dos acontecimentos que vão, digamos, de Bretton Woods à crise econômica internacional, uma fase da História, segundo ele, "em que o grau de incerteza com respeito ao futuro passa a cota da tolerância, pondo em risco a coesão social tornando particularmente difícil a tarefa de governar” (FURTADO, 1987, p. 161).

Nesse livro dá uma forte demonstração de sua capacidade de antecipação, quando descortina a fantástica expansão das atividades dos grandes bancos norte-americanos no exterior e do fenômeno da financeirização: “dessa forma, emergiu uma estrutura financeira de grandes dimensões, liberada da tutela dos bancos centrais e aliviados dos custos das reservas obrigatórias, com capacidade para criação autônoma da liquidez” (FURTADO, 1987, p. 199).

A expansão colossal das reservas monetárias acaba por gerar a formação de um sistema financeiro transnacional com ampla autonomia de ação. Esse processo termina por fortalecer as empresas transacionais, ao dar-lhes mais autonomia, mas que por outro lado desestabiliza os sistemas monetários nacionais. Nessa conjuntura, de transnacionalização acelerada das atividades produtivas, ampliar-se-á o co- 
eficiente de comércio exterior. O que traz, junto à necessidade dos ganhos de competitividade feitos a partir de investimentos pesados em tecnologia, que por sua vez limitará os empregos. A disputa entre tecnologia de ponta e emprego será "praticamente" resolvida com os processos de offshorização. Grandes conglomerados buscando trabalho barato e regulação reduzida ou inexistente nas regiões periféricas. Como acertadamente notou "foram as economias periféricas que se adaptaram às exigências de racionalidade econômicas das transnacionais” (FURTADO, 1987, p. 207).

Celso Furtado ainda não percebia os passos da economia chinesa e seu livro é, praticamente, centrado na preeminência mundial da economia norte-americana. Mas aponta a carreira armamentista com reflexos profundos na orientação do progresso tecnológico, que segundo ele, gerava incerteza com respeito ao futuro; bem como no estilo de desenvolvimento apoiado em economias de escala e no uso predatório de recursos não renováveis e uma padronização do consumo. Diz: “pouca dúvida pode haver de que a pressão na fronteira ecológica, com suas projeções na estrutura mundial de poder e seu impacto na orientação do progresso técnico, conduz a uma descontinuidade na história da civilização industrial” (FURTADO, 1987, p. 273). Não é pouca coisa a articulação que faz da triangulação armamentos - tecnologia - crise ambiental, fenômenos tão contemporâneos.

Concluo essa leitura de Celso Furtado com um parágrafo onde expressa a sua grandeza, não apenas como economista, mas como um teórico da política econômica internacional:

Um sistema econômico não é uma simples constelação de mercados cuja lógica possa ser explicada com base na teoria do comportamento dos agentes individuais. Ela pressupõe a existência de um quadro institucional e um poder regulador capaz de arbitrar os conflitos que se manifestam a todo momento em torno da apropriação 
e da alocação dos recursos escassos (FURTADO, 1987, p. 249).

Assim, o nosso autor entende que o sistema econômico não existe fora de um contexto político, como resultante de uma determinada estrutura de poder. É muito mais uma teia de relações onde o ambiental, o tecnológico e o cultural estão associados.

\section{Algumas reflexões teóricas}

A disciplina de RI é uma disciplina que segundo Acharya (2014) já não reflete “as vozes, experiências, reivindicações de conhecimento e contribuições da vasta maioria das sociedades e estados do mundo, e muitas vezes marginaliza aqueles que estão fora dos países centrais do Ocidente”. Há acadêmicos de RI ou de disciplinas chamadas de sociais, de diversas procedências que buscam, hoje, encontrar suas próprias vozes e reexaminar suas próprias tradições, ao ponto em que uma autora indiana se colocasse uma questão ontológica que projetou mundialmente suas reflexões (SPIVAK, 2010; COSTA LIMA e SOCCIO, 2016).

O que dizer da força do pensamento do filósofo camaronês Achille Mbembe, que articula em suas obras permanências e atualizações da colonialidade: racismo, violência de Estado e crítica ao capitalismo global. Diz ele:

Enquanto não tiver sido abolida a lógica da extração e da predação que caracteriza a economia política das matérias primas em África e, com ela, os modos existentes de exploração das riquezas do subsolo africano, poucos progressos se registrarão. O tipo de capitalismo que incrementa essa lógica alia maravilhosamente mercantilismo, agitações políticas, humanitarismo e militarismo (MBEMBE, 2014, p. 19).

Nosso desafio, num mundo que acelera suas transformações e tor- 
na obsoleta um conjunto de formas canônicas, seja nas ciências humanas seja nas relações internacionais, é traçar um caminho rumo a uma disciplina verdadeiramente inclusiva, reconhecendo suas múltiplas e diversas fundações (COSTA LIMA, 2013a).

Acharya formula a noção de uma "RI Global” que transcende a divisão entre o Ocidente e o Resto. Estruturando uma racionalidade que sempre esteve na base de todas essas violências históricas, descreve uma agenda de pesquisa que apóia a ideia de uma RI global. O elemento chave da agenda inclui estudos comparativos, estudos de sistemas internacionais que olhem para além da forma Westfaliana, conceituando a natureza e as características de uma ordem mundial pósocidental que poderia ser denominada como um Mundo Multiplex (utilizando justamente a imagem globalizada das salas de cinema), que amplia o estudo dos regionalismos e ordens regionais para além dos modelos eurocêntricos, criando sinergia entre abordagens disciplinares e estudos de área; expandindo novas investigações sobre a difusão de ideias e normas, e investigando as múltiplas e diversas maneiras pelas quais as civilizações se encontram, o que inclui interações pacíficas e aprendizado mútuo, mas também reconhecimento da história e, sobretudo, da expressão colonial dessa história que foi sempre negada ou silenciada.

O desafio de construir uma RI global não significa para ele uma abordagem de tamanho único; em vez disso, nos obriga a reconhecer a diversidade que existe em nosso mundo, busca um terreno comum que seja capaz de resolver conflitos; as múltiplas e diversas maneiras pelas quais as civilizações se encontram, o que inclui interações pacíficas e aprendizado mútuo.

A disciplina de Relações Internacionais (RI) reflete verdadeiramente a sociedade global em que vivemos hoje? Stanley Hoffmann 
(1977, p. 41) descreveu o campo como uma "ciência social norteamericana”. Isso não se sustenta mais no sentido físico ou geográfico. Nas últimas décadas, as escolas, departamentos, institutos e convenções de RI cresceram em todo o mundo. Mas a disciplina ainda precisa superar um desafio central relacionado às suas raízes britânicas e norte-americanas.

No ensino e na pesquisa, embora as interações entre o Ocidente e Oriente tenham se ampliado, ainda não foi possível superar, por exemplo, o avassalador predomínio das bibliografias ocidentais, mormente norte-americana. As universidades, os acadêmicos e as Editoras do Ocidente dão o tom dos temas e da agenda. Nesse universo fechado, os países do Sul são estudados apenas por especialistas ou como testes para determinadas teorias produzidas no Norte (ACHARYA e BUZAN 2007, 2010; WÆVER e TICKNER, 2009).

Em que pese sua grande popularidade, as narrativas dominantes de RI, teoria e métodos falham em corresponder à crescente distribuição global de seus assuntos e temáticas. The Global IR project, diz Acharya (2014, p. 649), transcende a distinção entre o Ocidente e o Oriente ou o que não é Ocidente ou qualquer categoria binária que seja exclusiva. Enquanto estas persistam como convenientes, elas perderão capacidade analítica, numa visão das RI Globais.

O pensador indiano entende que a Global RI não constitui uma teoria, mas uma aspiração para uma maior inclusão e diversidade em nossa disciplina. Em linhas gerais, a ideia da Global IR gira em torno de seis dimensões principais:

1. É fundada sobre um universalismo pluralista: não "aplicada a todos”, mas reconhecendo e respeitando a diversidade existente;

2. Baseia-se na história do mundo, não apenas na história greco- 
romana, européia ou americana;

3. Subsume, ao invés de suplantar, teorias e métodos de RI existentes;

4. Integra o estudo de regiões, regionalismos e estudos de área;

5. Evita o excepcionalismo;

6. Reconhece múltiplas formas de agência além do poder material, incluindo resistência, ação normativa e construções locais da ordem global.

Por que, pergunta ele, quando considerando as ideias que moldaram o pensamento de RI fazemos tanto de Tucidides, Maquiavel, Hobbes, Locke e Kant, mas não de Ashoka, Kautilya, Sun Tzu, Ibn Khaldun, Jawaharlal Nehru, Raul Prebish, Frantz Fanon e tantos outros (ACHARYA , 2014, p. 648); e eu aqui poderia incluir tantos grandes nomes, inclusive Edward Said, Celso Furtado, Anibal Quijano, Darci Ribeiro, Achille Mbembe.

Robert Cox (2002, p. 530) um autor crítico das RI, ao tratar do tema da universalidade oferece uma concepção alternativa de universalismo, que repousa em "compreender e respeitar a diversidade em um mundo em constante mudança”. Essa formulação rejeita a dicotomia falsa e politicamente inspirada entre o universalismo e o relativismo (COSTA LIMA, 2010a).

“A teoria, diz Cox, evolui através da controvérsia, através da história - como diria Hegel - entre distintos pontos de vista sobre a realidade; cada uma, uma perspectiva particular no tempo e no espaço” (2002, p. 25). Mas nos diz ainda que são dois os principais fatores que moldam a teoria, a saber: o primeiro é o movimento objetivo da história, que está continuamente lançando novas combinações de forças, 
que interagem umas com as outras e; o segundo, é a percepção subjetiva dos que contemplam estas forças com o objetivo de compreender e agir sobre o movimento da história (COX, 2002, p. 25).

Nosso desafio agora é traçar um caminho rumo a uma disciplina verdadeiramente inclusiva, reconhecendo suas múltiplas e diversas fundações. O caso da reflexão substantiva que faz o indiano Partha Chaterjee (2004, p. 237) sobre o lugar do estado colonial é representativa:

As formas do estado moderno foram importadas nestes países através da agência da regra colonial. As instituições da sociedade civil, nas formas em que elas tinham surgido na Europa, também fizeram sua aparição nas colônias, precisamente para criar um domínio público para a legitimação da dominação colonial. Este processo foi, no entanto, fundamentalmente limitado pelo fato de que o estado colonial poderia conferir ao colonizado apenas sujeição, não poderia dar-lhes cidadania.

Mas são muitos os pensadores indianos que refletem sobre a questão, a exemplo de Pannikar (2001, p. 108-111) quando afirma que “O que foi fundamental para a atitude colonial com o passado nativo, no entanto, não foi a sua apropriação, mas a negação de uma história válida para os colonizados”. Ou ainda, chamando a atenção para o próprio lugar das elites indianas, quando: “A inteligentzia indiana passou a ver sua própria história através do prisma colonial”. Aqui, Pannikar está muito próximo a Furtado, quando o brasileiro nos diz que as elites do país apenas viam no povo uma dimensão negativa (FURTADO, 1984, p. 23). ${ }^{3}$ Mas retornando à questão de Hoffmann acima pontuada, diz o internacionalista norte-americano que foi apenas o século XX que trouxe a democratização para a política externa e

3. "O povo era reduzido a uma referência negativa, símbolo do atraso, atribuindose significado nulo à sua criatividade artística” (FURTADO, 1984, p. 23). 
mesmo tendo vivenciando duas mortíferas guerras mundiais. As questões diplomáticas passaram dos cálculos de poucos para as paixões de muitos, tanto porque mais Estados aderiram ao jogo que tinha sido reservado a um pequeno número de atores (sobretudo europeus) e acima de tudo porque dentro de muitos estados, partidos e interesses estabeleceram ligações ou empurraram reivindicações através das fronteiras nacionais. O processo de descolonização africana está relacionada a essa ampliação, mas também expulsão dos ingleses da Índia ou a revolução comunista chinesa em 1949. Podemos ainda incluir a revolução cubana em 1959.

Hoffmann insiste que foi nos Estados Unidos que as relações internacionais se tornaram uma disciplina. Estudar a política externa dos EUA era estudar o sistema internacional e estudar o sistema internacional era igual a trazer a tona o papel dos EUA. "Pois era muito fácil assumir que os valores que apoiavam a pesquisa científica, o respeito à verdade, a liberdade de investigação, de discussão, e de publicação eram aqueles pelos quais Washington lutava nos assuntos internacionais” (HOFFMANN, 1977, p. 47).

$\mathrm{O}$ autor dizia ainda que os problemas que examinara haviam ocorrido, sobretudo, na América, porque a profissão dos especialistas de relações internacionais eram preponderantemente americanos. Essa predominância americana, nas relações Internacionais também tomou algumas características adicionais, essencialmente americanas (HOFFMANN, 1977, p. 56).

Acharya, por sua vez, aponta para uma das fraquezas proeminentes da liderança norte-americana na Ordem Mundial, a saber, o desejo normativo de universalidade que ignora variedades de atores e a multiplicidade de suas experiências. Mas há uma outra pergunta que o incomoda, que é especular sobre o que viria após a ordem Mundial 
dos Estados Unidos, nos anos vindouros?

Uma pergunta difícil de ser respondida, desde que para ele nenhum poder individual seria capaz de exercer uma influência sem o consentimento ou mesmo a participação de potências regionais em ascensão. O que viria a redefinir o quadro internacional. Para ele seria altamente improvável que o mundo voltasse à unipolaridade. Ele acredita que na complexidade das relações internacionais contemporâneas, que se desenharia um modelo hibrido de governança global, entre as grandes potências e os países emergentes e uma rede de ordens regionais. Nesse sentido, Acharya me parece muito otimista, ao acreditar numa governança harmônica com legitimidade. E muito embora Acharya minimize o padrão de governança global, ao afirmar que as nações dominantes abririam espaço para os movimentos sociais, para além dos estados, o que também, não está acompanhando os fatos.

A defesa que a Tese da Global IR faz é aquela que estaria enraizada na história mundial - muito mais do que na história do Ocidente - bem como nas idéias, instituições e perspectivas intelectuais diversas.

Segundo Acharya a designação do campo como "Global IR" não quer dizer reduzir a importância das regiões e dos regionalismos, muito menos a contribuição de áreas de estudo. Ao contrário, a $I R$ Global traz para o centro da discussão as regiões. Uma vez que o mundo não está se fragmentando em regiões, tampouco está se deslocando inexoravelmente na direção de uma globalização totalizante. Hoje vemos justamente o contrário, com o acirramento dos nacionalismos, reforçados pela experiência de Donald Trump e da ascensão de governos de direita ou extrema direita por todo o mundo.

Ao tratar da questão da Agência, diz Acharya que enquanto as principais teorias de RI veem o chamado Terceiro Mundo ou as Relações Sul-Sul ou do Sul Global como marginal à "história principal” da 
política mundial, algumas teorias críticas - incluindo aquelas associadas com o pós-colonialismo e escolas de dependência - na verdade prosperam nesta marginalidade presumida. Seus defensores têm razão ao criticar teorias mainstream para excluir o Sul global. Mas é uma luta que toma tempo. E a crise de 2008 tem feito a política e o sistema mundial caminharem para um neoliberalismo extremado na economia e um totalitarismo crescente na política, onde democracia e economia já não caminham no mesmo passo.

Vivemos um tempo histórico onde já não cabe a exclusividade do Ocidente. É necessário estabelecer programas sólidos de pesquisa que sejam capazes de descobrir novos padrões de Teorias e de Métodos a partir da História Mundial o que vem a ser um grande desafio para superar estereótipos cristalizados. Isso requer, como previu Acharya, descartar as estruturas estabelecidas a partir de Westphalia.

Hui (2004) argumenta, sobre a tendência dos teóricos de RI Ocidentais, de utilizar os conceitos de hierarquia e império, relacionados à história chinesa, após o período dos Estados Guerreiros ou dos Reinos Combatentes, ${ }^{4}$ para enquadrá-los como aberrações ao passo que entendem o modelo Europeu de Westphalia, descentralizado, como a norma correta do sistema internacional. Há grande desconhecimento de outros padrões estabelecidos muito antes, por chineses e indianos, com dinâmicas muito diferenciadas, e que precisam ser conhecidas e incorporadas à reflexão mais ampla das teorias de RI (COSTA LIMA, 2018; ZHAO TINGYANG, 2013).

4. Este período, antecede a unificação da China, feita por Qin Shi Huang. Ocorreu entre o século $\mathrm{V}$ a.C. até 221 a.C. e também fez parte da dinastia Zhou (uma das primeiras dinastias chinesas e a mais duradoura), que foi seguida pelo período das "Primaveras e Outonos". 


\section{A título de conclusão}

Penso que ficou mais clara a necessidade urgente de reconstruir a disciplina das Relações Internacionais, o que começa por trazer à luz as contribuições teóricas de todas as regiões, países e culturas. Isto só começará a existir de fato, quando as ementas das disciplinas de RI forem capazes de incluir os temas e autores que não sejam caros apenas aos centros desenvolvidos, de bibliografias internacionais que não sejam apenas as produzidas nos EUA, no Reino Unido, e nos demais países centrais. As academias da periferia, muitas delas sendo as primeiras a desvalorizar o próprio pensamento, a própria historicidade, acabam por reproduzir formas de pensar obsoletas. Findam por serem absorvidas intelectualmente pelas elites subdesenvolvidas.

Portanto, a leitura de Celso Furtado, de sua obra, de sua contribuição, não precisa ser vista ou compreendida de modo "envergonhado" por brasileiros, mas ao contrário, trata-se de uma reflexão diferenciada, que traz contribuições originais de um longo percurso histórico, com densidade analítica e teórica não apenas para aqueles da periferia, mas para toda humanidade. Na análise de muitos livros de Celso podemos observar sua riqueza de interpretação, ancorada em um lastro e bagagem histórica invejável, sua dimensão crítica, sua antecipação fenomenológica, sua abrangência multidisciplinar - História, Economia, Teoria do desenvolvimento e do Subdesenvolvimento, Epistemologia da Ciência, dinâmica do Capitalismo, Ecologia e mais do que nunca as ferramentas que utiliza no campo da Política Econômica Internacional.

Finalizo com uma passagem de Celso Furtado que diz muito de sua contribuição intelectual, de sua atualidade, muito além do apenas científico: 
Que os homens hajam tomado tanto tempo para perceber que a lógica do sistema capitalista - no qual a administração dos recursos não renováveis está subordinada a interesses privados - leva a um implacável empobrecimento da vida em um de seus aspectos fundamentais, que é o das relações do homem com a natureza, ficará como o maior paradoxo de uma civilização que pretendeu ter na razão seu princípio unificador (FURTADO, 2008, p. 222).

\section{Referências}

ACHARYA A. Global International Relations and Regional Worlds. International Studies Quarterly, doi: 10.1111/isqu.12171 (C) 2014 International Studies Association, 2014.

. The End of American World Order. Cambridge: Polity Press, 2014.

Advancing global IR: challenges, contentions and contributions, International Studies Review, 18(1): p. 4-15, 2016.

ACHARYA, A.; BUZAN, B. (eds.). Why is there no non-western international relations theory? reflections on and from Asia, Special Issue of International Relations of Asia Pacific, 7(3): p. 285-286, 2007.

. (eds.) Non-Western International Relations Theory: Reflections on and Beyond Asia. Oxford and New York: Routledge, 2010.

CHATERJEE, Partha. The Nation and its Fragments. Colonial and postcolonial Histories. In: The Partha Chattterjee Omnibus. New Delhi: Oxford University Press, 2004.

CHESNAIS, F. Finance Capital Today. Corporations and Banks in the Last Global Slump. Leiden: Brill, 2016.

COSTA LIMA, Marcos. Robert W. Cox e a Teoria Crítica nas Relações Internacionais. In: Costa Lima, Marcos... [et al]. Clássicos das Relações Internacionais. São Paulo: Hucitec, 2010a.

. Cultura e Pós-colonialidade: afinidades intelectuais entre Celso Furtado, Leopoldo Zea e os Subaltern Studies. In: D’Aguiar R. F. (Org.). Celso Furtado e a dimensão cultural do desenvolvimento. Rio de Janeiro: Epapers, v. 1, p. 250-273, 2013a. 
. Os Pesticidas: uma poderosa cadeia mundial, que envenena nossos alimentos e afeta a nossa saúde. In: Jornalismo \& Cidadania, n. 27, 2018.

- A Nova Teoria das Relações Internacionais Chinesa e a Ascensão do País: o conceito de Tianxia. In VADELL, Javier. A Expansão econômica e geopolítica da China no Século XXI. Belo Horizonte: Editora PUC Minas, 2018.

COSTA LIMA, Marcos (Ed at al). Clássicos das Relações Internacionais. São Paulo: Hucitec. 2010.

. Teóricos das Relações Internacionais. São Paulo: Hucitec, 2013.

COSTA LIMA, Marcos; BITU, Tieta Tenório; SALES, Gabriela L. Rômulo Almeida: espírito de planejador, demiurgo do estado brasileiro moderno. Texto produzido para o projeto Capes: Memórias Brasileiras: Biografias, 2018.

COSTA LIMA, Marcos; SOCCIO, Carolina Di Manno A. Visões do Sul: o Marxismo e o Pensamento Crítico nos Estudos Subalternos Indianos. Marília: Cultura Acadêmica Editora/Fapesp, p. 53-80, 2016.

COX, Robert. Universality in International Studies. In Critical Perspectives in International Studies, edited by Michael Brecher and Frank Harvey. Ann Arbor: University of Michigan Press, 2002.

. Political economy of a plural world: Critical reflections on power, morals and civilization. London: Routledge, 2002.

FURTADO, Celso. Subdesenvolvimento e estagnação na América Latina. Rio de Janeiro: Civilização Brasileira, 1968.

. Formação econômica da América Latina. Rio de Janeiro: Lia Editor S.A, 1969.

. O Mito do Desenvolvimento Econômico. 3 Ed. Rio de janeiro: Paz e Terra, 1974.

. O Brasil Pós-Milagre. Rio de Janeiro: Paz e terra, 1981.

. Cultura e desenvolvimento em período de Crise. Rio de Janeiro: Paz e Terra, 1984.

. Transformação e Crise na Economia Mundial. Rio de Janeiro: Paz e Terra, 1987. 
. Criatividade e dependência na civilização industrial. São Paulo: Companhia das Letras. Paz e terra, 2008.

. Formação Econômica do Brasil. In: Edição Comemorativa dos 50 Anos. Org: Rosa freire d’Aguiar Furtado, p. 49. São Paulo: Companhia das letras. 2009.

FURTADO, Rosa Freire d'Aguiar. Apresentação. In: Furtado, Celso. Formação Econômica do Brasil. Edição Comemorativa dos 50 Anos. Org: Rosa Freire d'Aguiar Furtado, p. 14. São Paulo: Companhia das Letras, 2009.

GILPIN, Robert. A Economia Política das Relações Internacionais, Brasília: Editora UNB, 2002.

HOFFMANN, S. An American Social Science: International Relations. Daedalus, v. 106, n. 3, Discoveries and Interpretations: Studies in Contemporary Scholarship, Volume I, p. 41-60, Summer 1977.

HUI, Victoria. Towards a Dynamic Theory of International Politics: Insights from Comparing Ancient China and Early Modern Europe. International Organization 58: 174-205, p. 2004.

KENNAN, George F. A Fresh Look at our China Policy. The New York Times Magazine, 24/11, 1964.

. American Diplomacy: 1900-1950. New York, 1951.

KLEIN, Naomi. This Changes Everything: Capitalism vs. The Climate. New York: Simon \& Schuster, 2015.

LATOUR, Bruno. OùAterrir? Comment s'orienter en politique. Paris: La Découverte, 2017.

MBEMBE, Achille. Sair da Grande Noite. Luanda. Mulemba, 2014.

África é a última fronteira do Capitalismo. Entrevista a Antonio Guerreiro, 9/12, 2018.

MORGENTHAU, Hans. A Reassesment of United States Foreign Policy. In: Politics in the Twenty Century v. II, 1958.

. The Revolution in the United States. Foreign Policy, [dados?] 1957.

MOORE, Jason. Capitalism in the Web of Life. London: Verso, 2015.

MOORE, Jason (Ed.) Anthropocene or Capitalocene? Nature, History and 
the Crisis of Capitalism. Oakland: PM Press, 2016.

NAYYAR, Deepak. A Corrida pelo Crescimento. Países em desenvolvimento na economia mundial. Rio de Janeiro: Contraponto, 2014.

PANNIKKAR, K.N. Culture, Ideology, Hegemony. New Delhi: Tulika Print, 2001.

PICKETTY, Thomas. Capital in the Twenty First century. Cambridge: The Belknap Press of Harvard University Press, 2014.

SPIVAK, Gayatri. Podem os Subalternos falar? Belo Horizonte: PUCMinas, 2010.

STENGERS, Isabelle. Au temps des Catastrophes. Resister à la barbarie qui vient. Paris: La Découverte, 2009.

STIGLITZ, Joseph. The Price of Inequality. How today's divided society endangers our future. New York: WW Norton \& Company, 2014.

TINGYANG, Zhao. The China Dream. Harvard Yenching Institute. Working Paper Series, 2013.

Rethinking Empire from a Chinese Concept 'All-under-Heaven' (Tian-xia), Social Identities, v. 12, n. 1, p. 29/41, January 2006.

WÆVER, Ole; TICKNER, Arlene B. Introduction: geocultural epistemologies. In: WÆVER, Ole; TICKNER, Arlene B. (Ed.). International Relations scholarship around the world. London: Routledge, 2009. 


\section{Resumo:}

Esse artigo tem como objetivo central considerar a obra do economista brasileiro Celso Furtado como um internacionalista. Através da análise de várias de suas obras, chegamos a conclusão de que questões abordadas por Furtado - a economia política mundial, desenvolvimento e subdesenvolvimento, a dinâmica do capitalismo, a ciência e tecnologia, os investimentos militares, a financeirização e as crises, inclusive a crise ambiental - são temas pertinentes e que tratam da natureza da economia política. A segunda parte do artigo introduz uma reflexão teórica sobre o porque da não existência de teorias nãoOcidentais nas relações internacionais? Para tanto, nos valemos das reflexões de autores, a exemplo de Amitab Acharya, Achille Mbembe, Partha Chaterjee entre outros que, ao lado de Celso Furtado, representam saberes e narrativas de maior diversidade e expressão cultural global.

Palavras-chave: Celso Furtado; relações internacionais; Sul Global; pós-colonialismo; eurocentrismo. 


\begin{abstract}
:
This article aims to consider the work of Brazilian economist Celso Furtado as an internationalist. Through the analysis of several of his books, we come to the conclusion that the issues addressed by Furtado - the world political economy, development and underdevelopment, the dynamics of capitalism, science and technology, military investments, financialization and crises, including environmental crisis - are relevant themes that deal with the nature of political economy. The second part of the article introduces a theoretical reflection on why is there no non-Western theories in international relations? For that, we use the thought of authors of authors such as Amitab Acharya, Achille Mbembe, Partha Chatterjee, Robert Cox among others, who, along with Celso Furtado, represent a knowledge and narratives of greater diversity and global cultural expression.
\end{abstract}

Keywords: Celso Furtado; International Relations Theory; Global South; Post Colonialism; eurocentrism. 